\title{
On the imaginative constructivist nature of design: a theoretical approach
}

\author{
Akın O. Kazakç1 ${ }^{1}$ \\ Centre de Gestion Scientifique, Design Chair, MINES PARISTECH \\ 60, Bd. Saint-Michel, 75272 PARIS cedex 06
}

\begin{abstract}
Most empirical accounts of design suggest that designing is an activity where objects and representations are progressively constructed. Despite this fact, whether design is a constructive process or not is not a question directly addressed in current design research. By contrast, in other fields such as Mathematics or Psychology, the notion of constructivism is seen as a foundational issue. The present paper defends the point of view that forms of constructivism in design need to be identified and integrated as a foundational element in design research as well. In fact, a look at the literature reveals at least two types of constructive processes that are well embedded in design research. First, an interactive constructivism, where a designer engages a conversation with media, that allows changing the course of the activity as a result of this interaction. Second, a social constructivism, where designers need to handle communication and negotiation aspects, that allows integrating individuals' expertise into the global design process. A key feature lacking to these well-established paradigms is the explicit consideration of creativity as a central issue of design.
\end{abstract}

To explore how creative and constructivist aspects of design can be taken into account conjointly, the present paper pursues a theoretical approach. We consider the roots of constructivism in mathematics, namely, the Intuitionist Mathematics, in order to shed light on the original insights that led to the development of a notion of constructivism. Intuitionists describe mathematics as the process of mental mathematical constructions realized by a creative subject over time. One of the most original features of Intuitionist Constructivism is the introduction of incomplete objects into the heart of mathematics by means of lawless sequences and free choices. This allows the possibility to formulate undecided propositions and the consideration of creative acts within a formal constructive process. We provide an in-depth analysis of Intuitionism from a design standpoint showing that the original notion is more than a pure constructivism where new objects are a mere bottom-up combination of already known objects. Rather, intuitionism describes an imaginative constructivist process that allows combining bottom-up and top-down processes and the expansion of both propositions and objects with free choices of a creative subject. We suggest that this new form of constructivism we identify is also relevant in interpreting conventional design processes and discuss its status with respect to other forms of constructivism in design.

Keywords: design, mathematics, Brouwer, Intuitionism, imaginative constructivism

\footnotetext{
${ }^{1}$ Corresponding author: akin.kazakci@mines-paristech.fr

t: +33140519208

f: +33140519065
} 


\title{
On the imaginative constructivist nature of design: a theoretical approach
}

\author{
Akın O. Kazakçı, \\ Centre de Gestion Scientifique, Design Chair, MINES PARISTECH
}

\begin{abstract}
Most empirical accounts of design suggest that designing is an activity where objects and representations are progressively constructed. Despite this fact, whether design is a constructive process or not is not a question directly addressed in current design research. By contrast, in other fields such as Mathematics or Psychology, the notion of constructivism is seen as a foundational issue. The present paper defends the point of view that forms of constructivism in design need to be identified and integrated as a foundational element in design research as well. In fact, a look at the literature reveals at least two types of constructive processes that are well embedded in design research. First, an interactive constructivism, where a designer engages a conversation with media, that allows changing the course of the activity as a result of this interaction. Second, a social constructivism, where designers need to handle communication and negotiation aspects, that allows integrating individuals' expertise into the global design process. A key feature lacking to these well-established paradigms is the explicit consideration of creativity as a central issue of design.
\end{abstract}

To explore how creative and constructivist aspects of design can be taken into account conjointly, the present paper pursues a theoretical approach. We consider the roots of constructivism in mathematics, namely, the Intuitionist Mathematics, in order to shed light on the original insights that led to the development of a notion of constructivism. Intuitionists describe mathematics as the process of mental mathematical constructions realized by a creative subject over time. One of the most original features of Intuitionist Constructivism is the introduction of incomplete objects into the heart of mathematics by means of lawless sequences and free choices. This allows the possibility to formulate undecided propositions and the consideration of creative acts within a formal constructive process. We provide an in-depth analysis of Intuitionism from $a$ design standpoint showing that the original notion is more than a pure constructivism where new objects are a mere bottom-up combination of already known objects. Rather, intuitionism describes an imaginative constructivist process that allows combining bottom-up and top-down processes and the expansion of both the propositions and the objects with free choices of a creative subject. We suggest that this new form of constructivism we identify is also relevant in interpreting conventional design processes and discuss its status with respect to other forms of constructivism in design.

Keywords: design, mathematics, Brouwer, Intuitionism, imaginative constructivism

\section{Introduction}

Is design a 'constructive' process? Certainly, the ultimate objective of a creative design process is to provide means (definitions, plans, blueprints etc) for allowing the construction of a new object. In addition to the final product, many intermediate representations are created and ideas are elaborated during a design process. In this respect, empirical accounts and observations of design processes suggest that design is a fundamentally constructive process. Yet, theories about design seldom take into account, if at all, the constructivist nature of design. In which sense design may be seen as a constructivist process? Are there different forms of constructivism in design? An extensive literature on models and theories of design bears on notions of progression, iteration or increments in the elaboration of some definition - without explicitly discussing a notion of constructivism. By contrast, in many research other areas such as Mathematics, Philosophy and Psychology, the notion of constructivism has been debated in depth and often as a foundational issue. The paper defends the idea that investigating whether design is a constructive process and what forms of constructivism exist in design is an important issue for consolidating theoretical underpinnings of design phenomena. 
Despite this lack of explicit consideration, at least two forms of constructivism can be identified in design literature. The first type is what we term interactive constructivism developing the notion that the interaction of the designer with some media is the engine through which design progresses. In this conception, a designer engages a kind of conversation with some media on her environment. She can observe unintended consequences of her actions or a new perceptual rearrangement of elements on the medium she uses for designing. This new interpretation may lead to changes in the course of the activity as a result of this interaction. Work from Schön (Schön 1983; Schön and Wiggins 1992) and more broadly from situated cognition (Gero 1998; Suwa and Tversky 2003) has been a major influence on this line of work. The second type is what we term social constructivism, which focuses on the social aspects of design that influences the course of a design process. In this line of work, each individual involved with the design process has its own unique world of expertise related to a particular aspect of the product. Integrating each individual's expertise into the global design process requires handling communication and negotiation aspects. In this sense, designs are collectively constructed. Work from Bucciarelli (Bucciarelli 1988, 1994) is one of the early examples that has been influential in design research. A key feature lacking to these wellestablished paradigms is the explicit consideration of creativity as a central issue of design.

Understanding the nature of the debate and issues in constructivism in other domains might shed some light on the issues related to the constructivism that need to be addressed in design. The present paper suggests a theoretical analysis for the inquiry of constructivism and its relation to design by considering the roots of this notion in mathematics. Constructivism can be traced back to the beginning of $20^{\text {th }}$ century where mathematics was in the midst of a foundational crisis. Contrasted point of views from pioneering mathematicians such as Frege, Hilbert and Russell were being elaborated while attempts were being made to build a solid foundation for mathematics. A Dutch mathematician, L.E.J. Brouwer contributed significantly to this foundational debate with his innovative research program and highly original results on Intuitionist mathematics (Brouwer 1907, 1908, 1948; Heyting 1975; van Dalen 1981, 1999). In Brouwer's work, mathematics is essentially a process of construction of (mental) objects by a mathematician. The activity of a mathematician, the so-called creative subject, is an exercise performed throughout time in such a way that any new mathematical object can only be constructed with whatever previous entities constructed thus far. However, this does not reduce mathematics to a mere combination determined beforehand and existing as a totality: The creative subject should construct the mathematical objects and she may do so with free choices - which give the mathematician the means to conceive new and unprecedented mathematical entities any time.

Intuitionist conception of mathematics has profound implications on what mathematics is and bears significant insights into its constructivist nature. First, it explains mathematical activity as a reasoning process performed over time. Second, it puts emphasis on the constructability of objects, rather than the truth of their existence. Third, it acknowledges the incompleteness of knowledge and the possibility of constructing new objects. Fourth, the construction of unprecedented and unpredicted objects is taken into account by a notion of creativity of the mathematician and her free choices. As we shall elaborate in depth throughout the paper, these points resonate with some fundamental properties of design processes. This is not surprising insofar as design can be defined as the elaboration of a definition of an object allowing its construction (or proving its existence, for that matter). Then, it becomes legitimate to suspect that mathematicians conduct a kind of design process in their everyday exercise: what is mathematics if not defining new (mathematical) objects with new and unprecedented properties? Under this perspective, it becomes interesting to analyze the reasoning process Intuitionists describe from a design standpoint in order to explore the limits of these similarities and to locate, if possible, notions that might be useful in the discussion of design constructivism. 
Arguably, the intricate relationship between mathematics and design deserves in depth analyses rather than any hasty yes or no conclusions, which, anyway, would not be possible considering the multiplicity of mathematical practices and outputs and the difficulty in capturing the act of design in one universal definition. To uncover issues in the constructivism debate that can be relevant in design theory, we need a theoretical description of design that allows situating and comparing different notions and theoretical constructs in Brouwer's Intuitionism with respect to design reasoning. This paper adopts the description that $\mathrm{C}-\mathrm{K}$ design theory provides as a framework for discussing and analyzing some of the aspects of Intuitionist Mathematics. This choice is motivated by several reasons. First, C-K theory provides mathematical interpretations of its core notions, facilitating thus a comparison with a mathematical approach to constructivism. Second, it gives a description of design process where creative acts are at the heart of the theory (Hatchuel and Weil 2009). This makes the theory suitable to uncover the relationship of creative acts and construction of objects in Intuitionism. Third, it describes design as the creation of new concepts and new objects on the basis of what is already known. These aspects point to strong similarities between Intuitionist Mathematics and C-K theory (Kazakci and Hatchuel 2009). Finally, literature about C-K design theory indicates strong relationships of the theory with the Forcing technique (Cohen 1963, 1964) in modern set theory. Incidentally, not only set theory is one of the main areas where Intuitionist Mathematics has had some of its most significant contributions, but also Forcing has some notable similarities with some intuitionist notions such as free choice sequences (Dummett 1977; Largeault 1993; Fraser 2006). This opens up the possibility to use intuitionist mathematics as a constructive foundational alternative for C$\mathrm{K}$ theory and some potential avenues for research have already been investigated (see e.g. (Kazakci 2009; Hendriks 2010; Hendriks and Kazakci 2010, 2011)).

The results from the confrontation of design theory with Intuitionist mathematics unfold in two parts. The first part presents Brouwer's work and philosophy and discusses it on the basis of $\mathrm{C}-\mathrm{K}$ design theory. The analysis concludes with a major thesis - the mathematical creation process Brouwer describes can be characterized as imaginative constructivism where the construction of objects proceeds towards conceivable and imagined properties. This interpretation is new for the philosophy of mathematics and it stands in contrast by what we might call a pure constructivism. The second part discusses the relevance of this notion for design research using a historically important design project, the making of an atomic bomb (Groves 1962; Lenfle 2008, 2011). Our analysis of the case demonstrates that notions from intuitionist mathematics and imaginative constructivism enable capturing and describing significantly creative and constructive aspects of the Manhattan project, whereas, neither interactive, nor social constructivism takes into account the imaginative nature of genuinely creative acts and radical changes.

The plan of the paper is as follows: In section 2, the paper gives a brief overview of interactive and social constructivism in design. In section 3, our general approach and the analytical framework we use (C-K theory) are presented. In Section 4, we start reviewing Brouwer's work in some detail. Major concerns of intuitionism, such as the emphasis on definability, the reject of the excluded middle principle and free choice sequences, that are relevant from a design theory perspective are covered. In Section 5, an analysis of Intuitionism is provided. We first review and reposition its basic principles with respect to $\mathrm{C}-\mathrm{K}$ theory to highlight strong similarities. Then, we argue that interpreting Intuitionist mathematical process as purely constructivist, as it has been done in the literature, is reductionist. Instead, we propose a new interpretation called imaginative constructivism. In Section 6, we describe the Manhattan project in relation with imaginative constructivism. Section 7 discusses some further points and concludes the paper with a summary. 


\section{Forms of constructivism in design}

\subsection{Design as interactive constructivism}

One of the major paradigms that underlie current design research bears on the situated approach to cognition (Suchman 1987; Clancey 1997; Anderson 2003). In situated cognition, which arose as a reaction to Cartesian, symbolic conceptions of intelligence, reasoning and action are phenomena emerging out of the interaction of the subject with his environment. This line of thought has been strongly adopted in design research and has been widely disseminated (Gero 1998; Roozenburg and Dorst 1998; Suwa et al. 1999; Gero and Kulinski 2000; Suwa and Tversky 2003). A salient reference on the study of situatedness in design is the work by Schön and colleagues on the use and creation of knowledge in the professional world (Schön 1983; Schön and Wiggins 1992). Criticizing the technical rationality and logical positivism predominant in the design literature at the 80 s, Schön is interested in the phenomenological components of design activity and professional work in general. Schön, following Polanyi, accepts that much of our knowledge is tacit and it can only be revealed within a particular context and task during the action. The knowing is in the action. However, knowing-in-action is not always sufficient since there are surprises and impasses that require the professional to step out of her routines. The ability to cope with these situations necessitates thinking what is being done while the activity is happening. Reflection-in-action is thus the ability to monitor and control the course of the activity in search for novelty.

Schön and Wiggins (1992) building on these ideas analyze the particular activity of designing. They defend the notion that design research cannot ignore that designers interact with a medium. Design is introduced as a conversation between the materials and the designer. When a designer makes a move to apply a change in the design materials, she is going to notice the consequences of this action, which, in some cases will be unexpected. Seeing these emergent properties in the design medium will provoke changes in the original goals of the design process, which, in turn will trigger new moves and so on. This idea that the interaction with some design medium is the engine through which design progresses has been largely adopted in design literature, particularly in works that consider design in relation with sketching (e.g. in industrial design or architecture) (Edmonds and Candy 1999; Suwa et al. 1999). For instance, in a series of experimental studies Suwa and Tversky (2003) studied how designers conduct a visual thinking process using their representations: they often start with some tentative and loose sketch, not being able to conceive or integrate all the relevant aspects to their design right from the beginning. By reinterpreting what they have laid down so far, they progressively elaborate on the initial sketches. Suwa and Tversky (2003) called this a constructive perception process where conceptual reorganization skills are necessary in order to infer functional relationships and think of new rearrangements of elements.

\subsection{Design as a social constructivism}

Another stream of reactions to a restrictive vision of design as a technical process emphasized the importance of social processes in design (Bucciarelli 1988; Dougherty 1992; Bucciarelli 1994). For instance, Bucciarelli (1994) opposes strongly to a savant approach of design as applied science and instrumentation. According to him, this traditional and dominant vision of engineering design reduces the design process to technical matters and obscures the real phenomena to be studied. Adopting an ethnographic approach to the study of design, he rather considers design as a social process "occurring in a sub-culture as a form of interaction with the surrounding culture". This social process includes any participant who has a "legitimate say in the process whose words, proposals, claims and supplications matter and contribute to the final form of the product" (Bucciarelli 2002). Bucciarelli takes this multiplicity of point of views into account by the notion of "object-worlds". Object worlds refer to the worlds of individual effort where an engineer, working for the most part alone, applies his or her 
expertise to particular tasks appropriate to his or her discipline. Different participants with different competencies, skills, responsibilities and interests inhabit different worlds. As such, while admittedly working on the same object of design, they see the object differently and they use different languages (Bucciarelli 1988, 2002). Bucciarelli claims that translation is not possible, and decomposition is impossible because other objectworlds are of interest to other participants. It is an unavoidable part of design to define "interfaces" (rather than translate) and this requires a constant social interaction. Engineers spend a significant portion of their time in documenting and communicating much of it in the form of formal or informal 'negotiations'. The design process is thus a socially constructed process.

Social constructivism has also been used within the context of design support tools. For instance Subrahmanian and colleagues (Subrahmanian et al. 1993), see also (Davis et al. 2001) emphasized the importance of social contexts in the use of any formal models. They stress the importance of building systems that offer flexibility in expression and malleability, since different designers express themselves differently and based on the premise that the tool should allow the possibility to have multiple models corresponding to those different point of views. Creating these shared information spaces would help the creation of shared meaning and progressing the design by mutual interaction.

\section{Background and approach: Using a formal design theory for interpreting intuitionist constructivism}

In order to analyze intuitionism from a design perspective, we are going to use a formal description of design reasoning given by C-K theory (Hatchuel and Weil 2009). The section starts by pointing out a common concern that connects mathematics and design. Then, we present fundamentals of C-K theory.

\subsection{Defining and building new objects: a common foundational concern for Mathematics and Design}

A central issue in design theory is the definition of objects. Indeed, one of the most common definitions for design is "building a definition of an object allowing its construction or implementation" (Evbuomwan et al. 1996). Yet, what is defining an object? In the field of design, it does not seem useful to adopt extensional definitions (e.g. enumerating and naming all the physical occurrences of an object), nor, does it seem reasonable to accept a static, dictionary-based approach (Hatchuel 2002, 2008). On the contrary, it is arguable that innovations require shifts in the definition of objects, thus creating new classes of objects (Le Masson et al. 2010). This presupposes the existence of (abstract) intensional definitions - definitions of classes of objects by their common attributes or properties.

As we shall see shortly, the issue of definition is also fundamental for C-K design theory. A concept space is a hierarchy of partial and intensional definitions that are underconstruction in $\mathrm{C}$ space. The shift of a definition - its expansion - progresses while triggering attempts to build new objects corresponding to that definition in $\mathrm{K}$ space (Kazakci 2009). New definitions imagined in C space guide the construction of such extensional objects in K space. What can be defined depends on what can be conceived.

The debate about the nature of mathematical objects is intense in mathematics and philosophy as well (Benacerraf and Putnam 1983). Over the last century, a variety of schools and point of views has seen rise about the meaning of existence, definability and conceivability of mathematical objects (Field 1980; Chihara 1990; Burgess and Rosen 1997; Lakoff and Nunez 2000). A much-debated object is that of a "number" (Benacerraf 1965; Frege 1983). How to define numbers is a fundamental issue since it is directly related to hard problems of mathematics such as the continuum problem or the nature of 
infinity. An elementary result in Analysis states there are as much real numbers between the unit interval as in the whole real line. Both sets are infinitely expandable (Hatchuel and Weil 2007) so it is always possible to find or construct a number different than all the other number objects discovered so far. It is precisely on this issue that Brouwer has introduced a variety of novelties describing processes by which numbers can be defined using constructive means but without compromising the expandable nature of the objects.

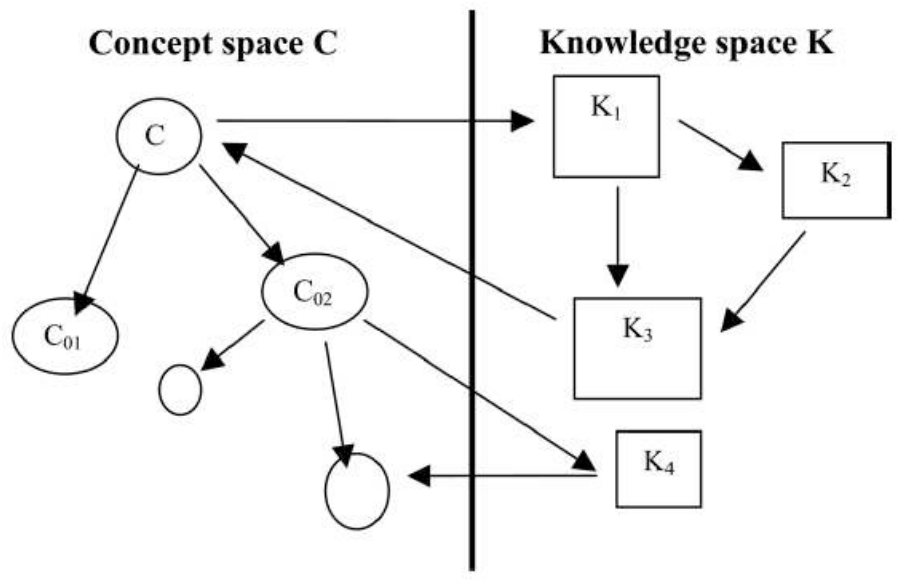

Figure 1. Concept and knowledge spaces, (Hatchuel and Weil 1999, 2002)

\subsection{Overview of C-K theory}

Hatchuel and Weil (Hatchuel and Weil 1999, 2002, 2003, 2007, 2009) propose a theory of design reasoning which captures some of the fundamental properties of design reasoning process as a conceptive reasoning process. The theory is based on the distinction and interaction between two spaces; figure 1;

- Knowledge space A knowledge space represents all the knowledge available to a designer (or to a group of designers) at a given time. These are propositions that the designer is capable of declaring as true or false; i.e., propositions whose logical status are known to the designer (e.g., some phones are mobile).

- Concept space A concept space represents propositions whose logical status are unknown and cannot be determined with respect to a given knowledge space. These are propositions that can be stated as neither true, nor false by the designer at the moment of their creation (e.g., some phones prevent heart attacks).

In $\mathrm{C}-\mathrm{K}$ theory, concepts are descriptions of an object of the form "C: there exist an object $\mathrm{x}$ with the properties $\mathrm{p}_{1}, \mathrm{p}_{2}, \ldots, \mathrm{p}_{\mathrm{n}}$ such that $\mathrm{C}$ is undecided with respect to $\mathrm{K}$ ". In other words, the designer who created the concept is not able to tell whether such thing is possible or not at the moment of creation. A design process (or alternatively, a conceptive reasoning process) begins when such an undecided formula is created. A designer can then elaborate the initial concept by partitioning it - that is, by adding further properties to C. Current writings about $\mathrm{C}-\mathrm{K}$ theory distinguish two kinds of partitioning. Restrictive partitions add to a concept a usual property of the object being designed and expansive partitions add to a concept novel and unprecedented properties (Hatchuel and Weil 2003). Creativity and innovation are possible due to expansive partitions: such partitions lead to fundamental revision of the identity (or definition) of objects. Since concepts are elaborated by partitioning, the concept space has a tree structure.

Concepts, although different than knowledge in their logical status, are created from knowledge. For this reason, different designers with different knowledge spaces may create different concepts. A concept space can only be defined with respect to a knowledge space - concepts are $K$-relative.

When elaborating a concept space, a designer might use his or her knowledge, either to partition further the concepts, or to attempt a validation of a given concept. This last type 
of operation is called K-validation and it corresponds to the evaluation of a design description using knowledge. The result of a $\mathrm{K}$-validation is positive, if the designer acknowledges that the proposition "there exist an object $\mathrm{x}$ with properties $\mathrm{p}_{1}, \mathrm{p}_{2}, \ldots, \mathrm{p}_{\mathrm{n}}$ " is true. The result is negative, if the knowledge available to the designer allows him to state that such an object cannot be built. In both cases, the conception ends for the concept that has been validated (or, rejected). The reasoning may continue by creating new concepts or other (unexplored) branches of the concept tree.

Often the validation of a concept is not readily possible. Due to the expansions of the concept space, object definitions whose instances are not known by the designer have been created. In order to validate concepts, new knowledge warranting the existence conditions of such an object should be acquired. In terms of the theory knowledge should be expanded. The expansion of knowledge space is called K-expansion. The central proposition of $\mathrm{C}-\mathrm{K}$ theory is thus "design is the interaction and dual expansions of concepts and knowledge" (Hatchuel and Weil 1999, 2002, 2009).

\section{Brouwer's Intuitionist mathematics}

Let us now present Brouwer's philosophy and the basic notions of Intuitionist Mathematics. We will start by describing some foundational debates that influenced Brouwer's work. Then, the first and the second acts of intuitionism will be presented. Some of the main ideas and notions such as the Intuitionist notion of "existence", the reject of the "law of the excluded middle" and the basics of Brouwerian set theory will be covered.

\subsection{Pre-intuitionist debate on definability, conceivability and existence of objects}

Let us start by describing the context in which Brouwer's work developed in order to better understand Brouwer's position and his contribution. Until the introduction of nonEuclidean geometry, mathematics was widely conceived as a mixture of empirical knowledge and abstractions (Largeault 1993). Brouwer called this "the point of view of observation". With the introduction of mathematical entities such as spaces, species of numbers, transfinite, ... this observational point of view has become obsolete, as it was difficult to find concrete counterparts of such objects. Especially, the introduction of the transfinite by Cantor (and sets of uncountable cardinalities) and the use of abstract choice principles (which never gave any individuals but classes - that may not contain discernable entities) have seen strong objections from many pioneering mathematicians at the beginning of $20^{\text {th }}$ century.

An intense foundational debate concerning the nature and the practice of mathematics has taken place. Russell and Hilbert have attempted to replace the previous spatial foundations of mathematics with logical and axiomatic foundations. While Russell has defended the appropriateness of logical foundations (Russell 1903), reconstructing, with Whitehead, the foundations of mathematics using logic (Russell and Whitehead 1910), Hilbert conducted a massive research program to build mathematics on axiomatic foundations (Hilbert 1927). These two approaches, reconcilable in many respects, have strong syntactic and linguistic underpinnings.

An alternative set of ideas can be found in the works of a group of prominent French mathematicians including Borel, Baire, Lebesgue, Hadamard and Poincaré. The group, called pre-intuitionists by Brouwer, has criticized thoroughly the new abstract mathematics. Poincaré expressed his doubts about the logical and axiomatic approaches of Russell and Hilbert: "The syllogism cannot reveal anything fundamentally new. If all mathematical propositions can be derived from others, how would mathematics not be reduced to an immense tautology?" Presuming there was more to mathematics than syllogistic reasoning, Poincare distinguishes two kinds of minds; the analyst and the 
geometrician. The former uses logic and deduction while the latter uses intuition (Largeault 1993). "The logic is sure, but creates nothing; the intuition is creative but fallible." Much as Poincaré qualifies Intuition as fallible, by underlining its importance, he puts emphasis on the role of conception in mathematics (Largeault 1993). Here lies the most consensual and essential idea that connects pre-intuitionists: what is definable is what is conceivable. Being conceivable (not necessarily by a concrete imagination) is a necessary condition for existence. For instance, from this perspective, the notion of actual infinity (infinite sets whose constructions are actually terminated) becomes criticizable. Baire, Borel and Poincare have insisted that our mind is capable only of a finite number of acts of thought. Consequently, we can only conceive finite objects and consider only objects defined by a countable number of conditions.

\subsection{First Act of Intuitionism: Mathematics as the study of mental objects}

Though Brouwer agreed with pre-intuitionist on the above issues, he went beyond their critical reactions by offering an essential change in perspective and an alternative way to proceed. Beginning with his thesis in 1907, Brouwer started to build a new way of looking at mathematics. According to him, mathematics is a mental activity completely independent of the outside world, taking place in the mind of a mathematician - the creative subject. This activity takes place over time and thus, mathematics is a constructive activity. Going completely to the opposite direction of Russell, he postulated that this mental activity, and thus, mathematics is independent and prior to all language:

"One cannot inquire into the foundations and nature of mathematics without delving into the question of the operations by which the mathematical activity of the mind is conducted. If one failed to take that into account, then one would be left studying only the language in which mathematics is represented rather than the essence of mathematics." (Brouwer 1907, 1908).

This particular view of mathematics is called the First Act of Intuitionism. In Brouwer's words, the first act

"[...] completely separates mathematics from mathematical language, in particular from the phenomena of language which are described by theoretical logic, and recognizes that intuitionist mathematics is an essentially languageless activity of the mind having its origin in the perception of a move of time, i.e. of the falling apart of a life moment into two distinct things, one of which gives way to the other, but is retained by memory. If the two-ity thus born is divested of all quality, there remains the empty form of the common substratum of all two-ities. It is this common substratum, this empty form, which is the basic intuition of mathematics. (Brouwer 1952)

Hence, the basic intuition Brouwer is proposing is based on the perception of the passage of time - the progression of a reasoning individual from one moment to the next.

The emphasis on the languageless nature of mathematics puts Brouwer's mathematics in complete opposition with Russell's efforts of reconstructing mathematics using logic. Although Intuitionism is not against logic (in fact, Brouwer was the first to propose a logic based on intuitionist principles), it firmly states that mathematics is prior to logic. "For intuitionist mathematics every language, including the formalistic one, is only a tool for communication. It is in principle impossible to set up a system of formulas that would be equivalent to intuitionist mathematics, for the possibilities of thought cannot be reduced to a finite number of rules set up in advance. [...] For the construction of mathematics it is not necessary to set up logical laws of general validity; the laws are discovered anew in each single case for the mathematical system under consideration." (Heyting 1983b, a). 


\subsection{The existence of mathematical objects: an emphasis on the constructability}

Brouwer's view of mathematics as a mental, progressive and constructive activity has implications for the definability and existence of mathematical objects. According to Brouwer, for mathematical objects, "to exist" means "can be constructed" (Heyting 1983a). If this were not the case, then "to exist" would have a metaphysical meaning. Although Brouwer and his followers have no objection to any particular metaphysical theory, they believe that the study of mathematics cannot be related to these; it is something much simpler, more immediate than metaphysics - the study of mental mathematical constructions (Heyting 1983a). Heyting, one of the major contributors to Brouwer's program, gives the following explanation about the intuitionist view on the existence of mathematical objects (Heyting 1983b):

"We do not attribute an existence independent of our thought; i.e., a transcendental existence to the integers or to any other mathematical object. Even though it might be true that every thought refers to an object conceived independently of it, we can nevertheless let this remain an open question. In any event such an object need not be completely independent of human thought. Even if they should be independent of individual acts of thought, mathematical objects are by their very nature dependent on human thought. Their existence is guaranteed only insofar they can be determined by thought."

Although acknowledging that mathematical objects may be referring to the outside world, Heyting defends that those cannot be conceived independently of the human thought. The ideal mathematical objects are ascertained to exist if they can be constructed and verified by thought. Hence, the Intuitionists defends that the existence of an object depends on whether it can be mentally constructed.

\subsection{The reject of the law of excluded middle: accepting undecided propositions}

The above view on the existence of mathematical objects has some implications regarding the nature of mathematical propositions. In intuitionist mathematics, a proposition affirms the fact that a certain mathematical construction has been affected. In other terms, a proposition $P(a)$ about a mathematical object $a$ means "there is a way of constructing an object $a$ having a property $P$ ". This view of existence as constructability and mathematics as the study of mental constructions accomplished over time led Brouwer to reject the idea that every mathematical assertion should be either true or false. This principle, known as the Law of the Excluded Middle (LEM) is not tenable for the kind of mathematics Brouwer proposed, since, to be able to say that $P(a)$ or its negation, $\sim P(a)$, is true for every proposition $P$ and every object $a$, we must have a general method for constructing any object having any property. As we have no such method, we have no right to use such a principle. Acknowledging such a principle would mean that laws of mathematics are general and refer to the objects of the world, independently of our knowledge. This is obviously in contradiction with the kind of mathematics Brouwer advances. $^{2}$

One of the consequences of considering undecided propositions is the reject of LEM. Since mathematics is an activity carried out over time, there may be stages where neither a property $P(a)$ of an object $a$, nor its negation $\sim P(a)$ has yet been decided by the creative subject.

\footnotetext{
2 It should be noted however that LEM holds in finite domains and the reject concerns mainly infinity: “Of greater theoretical interest is the fact that LEM is also held to be valid in cases where one is operating in a strictly finite domain. The reason for this is that every construction of a bounded finite nature in a finite mathematical system can only be attempted in a finite number of ways, and each attempt can be carried through to completion, or to be continued until further progress is impossible. It follows that every assertion of possibility of a construction of a bounded finite character can be judged. So, in this exceptional case, application of the principle of the excluded third is permissible." Heyting [12].
} 
While the reject of the LEM is only natural for intuitionist mathematics, let us note that it is a very controversial issue and it is widely held as unacceptable by many leading mathematicians such as Hilbert: Denying a mathematician use of the principle of excluded middle is like denying an astronomer his telescope or a boxer the use of his fists. To prohibit existence statements and the principle of excluded middle is tantamount to relinquishing the science of mathematics altogether (Hilbert 1927).

\subsection{Second act of intuitionism: generative power of intuitionism}

Contrary to the first act, which is critical and destructive, the second act of intuitionism is creative and constructive (Largeault 1993). Brouwer sets himself the task to deal with the continuum within the Intuitionist paradigm. However, the consideration of infinite sets as completed totalities that has been the standard mathematical practice since Cantor and Dedekind, cannot be accepted from an intuitionist standpoint. By contrast to the actual, completed infinity in the classical approach, the intuitionist approach envisions infinity as potential. Brouwer rejects the actual infinity since such objects are inconceivable by a mind that disposes only of a finite number of acts of thought. In order to construe infinity as potential infinity, he uses the notion of infinitely proceeding sequences - sequences of mathematical objects that proceed to infinity but never achieve it.

In fact, pre-intuitionists have already used such sequences to define real numbers and to tackle the notion of continuum (e.g. by means of classes of equivalence of Cauchy sequences for defining sets of real numbers). Yet, this was being done by sequences that were 'closed'. Brouwer realized that restraining oneself to lawlike sequences is highly limitative: the real numbers that can be defined by means of such sequences can only offer a discrete infinity and a reduced continuum. Therefore, he suggests extending the classical notion of infinitely proceeding sequences to that of (free) choice sequences (or, lawless sequences): infinitely proceeding sequences of mathematical objects of which the construction is not fixed by a predetermined law or algorithm but for which terms can be chosen arbitrarily at any stage of their construction by a creative subject.

One of the implications concerns the nature of continuum and infinity. Since mathematics is a mental construction based on the step-by-step activity of a mathematician, any notion of infinity is potential - not actual. The view of infinity as potential and the continuum as a never completed totality brings Brouwer close to pre-intuitionists who expressed doubts on the transfinite and inconceivable mathematical objects.

Van Dalen (van Dalen 2005) remarks that, compared to the classical point of view, Brouwer's universe does not get beyond $\omega_{1}$ (there is no transfinite and actual infinity). But, what it lacks in 'height' is compensated in 'width' by the extra fine structure that is inherent to the intuitionist approach and its logic. This fine structure allows mathematically thinking the continuum in its very indeterminacy and errancy vis-à-vis discrete enumeration, and to do this without letting the continuum dissolve into an unintelligible mystery (Fraser 2006).

\subsection{Spreads and Species: Intuitionist counterparts of the notion of "Set"}

As Brouwer explains (Heyting 1975; Freudenthal 1976), the second act recognizes the possibility of generating new mathematical entities, firstly, in the form of infinitely proceeding sequences $a_{1}, a_{2}, \ldots$, whose terms are chosen more or less freely from mathematical entities previously acquired; in such a way that the freedom of choice [...], at any stage may be made to depend on possible future mathematical experiences of the creating subject; secondly, in the form of mathematical species, i.e. properties supposable for mathematical entities previously acquired, and satisfying the condition that, if they hold for a certain mathematical entity, they also hold for all mathematical entities that have been defined to be equal to it.

With the second act, Brouwer replaces the classical notion of set by separating it to two 
notions; spreads and species. A spread is a law that regulates the construction of infinitely proceeding sequences. The law determines

- $\quad$ which mathematical entities are accepted as the initial segment of the sequence and

- which elements are allowed to further the sequence (in such a manner that there is always at least one element that should be accepted).

Figure 2 shows an example spread that corresponds to a full binary spread, i.e., infinitely proceeding sequences of $0 \mathrm{~s}$ and $1 \mathrm{~s}$ starting from the empty set. A spread can be narrowed down by an operation called hemmung (restriction, in German) to more specific spreads (e.g. the full binary spread can be narrowed down to sequences starting with $<0,0,1>$ ).

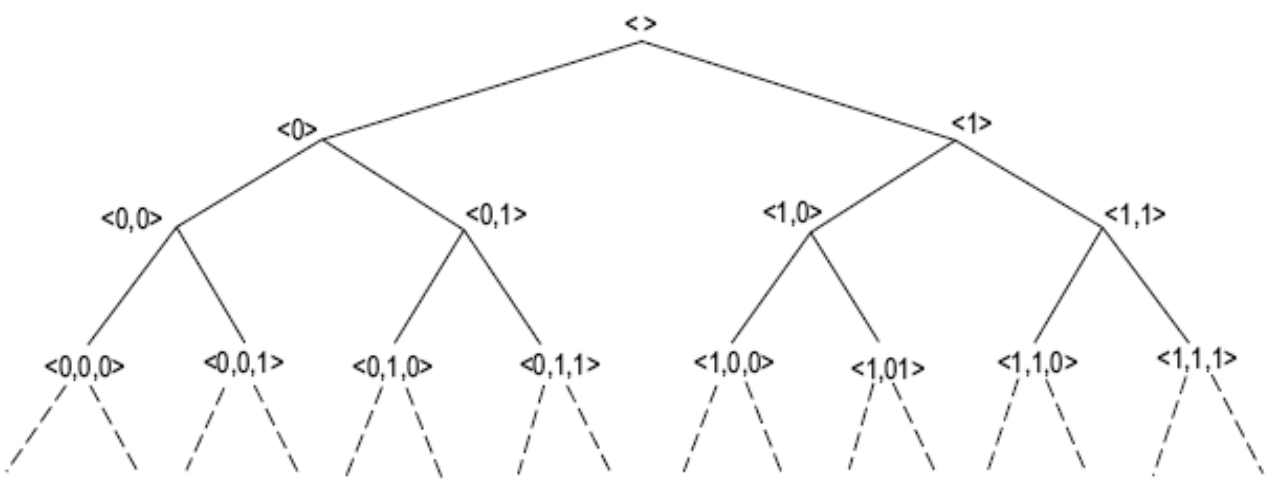

Figure 2. A graphical representation of the full binary spread.

A species is a property or a relation (or a collection of properties and/or relations). The elements of a species are precisely those that verify the condition determined by the definition of that species - a condition for which we should have a definite way of knowing what counts as a proof of it. For instance, we can think of a species (on the full binary spread above) determined by the property $P$ "the sum of whose first $n$ terms is pair". For any given element (a branch of the spread corresponding to an infinite sequence), it is possible to determine whether this property holds for any given $n$.

The existence of a species is warranted only after a choice sequence having the corresponding property can be built (or an algorithm that will allow its construction is given). On the other hand, any property a choice sequence has can only be based on an initial segment of it, since it is not completed and there are infinitely many ways to further it.

Clearly, the notion of spread is an extensional one whereas the notion of species is intentional (Dummett 1977). The introduction of species plays the role of the axiom of comprehension of classical mathematics. Spreads are on the side of 'becoming' whereas species are on the side of 'being' (Largeault 1993). The possibility to generate new mathematical entities (using whatever entities that were previously acquired) with infinitely proceeding sequences and to construct new and unprecedented species provides to the subject the necessary means to study the continuum. Most of the original contributions of Intuitionist Set Theory, such as the Bar induction theorem or the Fan theorem (Dummett 1977), can be interpreted only due to the introduction of ingeniously conceived lawless sequences used in the proofs. This is also true for results claiming the invalidity of LEM. 


\section{An analysis of intuitionist mathematics from a design point of view}

\subsection{Intuitionist mathematics as a design process}

One of the most controversial traits of Brouwer's philosophy is his explicit reference to the mathematician in order to argue and justify the principles by which mathematics should be done. This is quite different, for instance, from the approach of Hilbert who proposed the axiomatic method as a general method for the mathematics. By contrast to him and still others, Brouwer speaks about a subject - the creative subject, the mental constructions of this subject and her freedom to choose the way the construction should proceed. This is not to suggest that truth is relative, but to address the question "what mathematics is" by pointing out "who does the mathematics". This induces a unique set of key properties to Intuitionist Mathematics that bring it closer to creative reasoning as described by C-K design theory. Table 1 summarizes some correspondences between the notions of these theories. The similarities are striking. Let us discuss some of those foundational features.

\begin{tabular}{|c|c|}
\hline Notions of C-K theory & $\begin{array}{c}\text { Brouwer's ideas and notions of } \\
\text { Intuitionism }\end{array}$ \\
\hline Designer & $\begin{array}{l}\text { The mathematician; the creative subject, } \\
\text { the constructor }\end{array}$ \\
\hline Knowledge & $\begin{array}{l}\text { - All the objects, in particular sequences, } \\
\text { spreads and species that have been acquired } \\
\text { so far. Those include lawlike sequences. } \\
\text { - All the (proven) properties of the objects } \\
\text { constructed so far. }\end{array}$ \\
\hline Concepts & $\begin{array}{l}\text { Species that are yet unproven to exist; } \\
\text { propositions that are yet undecided }\end{array}$ \\
\hline Objects & $\begin{array}{l}\text { Infinitely proceeding sequences, spreads, } \\
\text { species (and other conventional objects } \\
\text { such as the natural and rational numbers) }\end{array}$ \\
\hline Object of which the design are finished & Finite objects or Lawlike sequences \\
\hline Objects that accept "expansions" & Lawless sequences \\
\hline Expansions & $\begin{array}{l}\text { Properties or objects obtained by "Free" } \\
\text { choices }\end{array}$ \\
\hline Restrictions & $\begin{array}{l}\text { Properties or objects obtained by } \\
\text { Hemmung }\end{array}$ \\
\hline Operators / Interactions of the $\mathrm{C}$ and $\mathrm{K}$ & - \\
\hline
\end{tabular}

Table 1. Correspondences between notions of C-K design theory and Brouwer's work

\subsubsection{Reasoning about (mental) objects}

Brouwer rejects the idea of mathematics as a study of symbols or a language based activity in favor of a mathematics studying objects. As we have underlined in section 3.1, this "elaboration of objects" perspective is a common concern both to mathematics and to design theory in general. Brouwer's mathematics explicitly acknowledges the place of objects in mathematics. For Intuitionists, any symbolic representation or formal language can only be a tool for communication - not the core of mathematical activity. The activity itself is happening in the mind of the mathematician and it consists in the construction of (mental) objects.

\subsubsection{Progressing through knowledge stages}

A second aspect that brings Intuitionist mathematics closer to a design process is the progressive nature of the reasoning activity; Figure 3. Starting with his foundational writings, Brouwer emphasizes the idea of progression of the reasoning and learning 
(Brouwer 1907, 1908) (see also paragraph 3.2). This implies in turn, the incompleteness of knowledge. For any given time, there may be truths that may not be known yet and objects that have not been constructed so far. This can also be seen in two major formal models describing the evolution of Intuitionist knowledge; the Theory of Creative Subject (see next section) and Kripke's semantics for Intuitionist logic (Kripke 1965). This fundamental feature is also part of $\mathrm{C}-\mathrm{K}$ theory and any realist design situation. New objects with new properties become known, as the reasoning progresses but the knowledge may never be completed - otherwise there would be no design, but only selection (Hatchuel 2002; Hatchuel and Weil 2002).

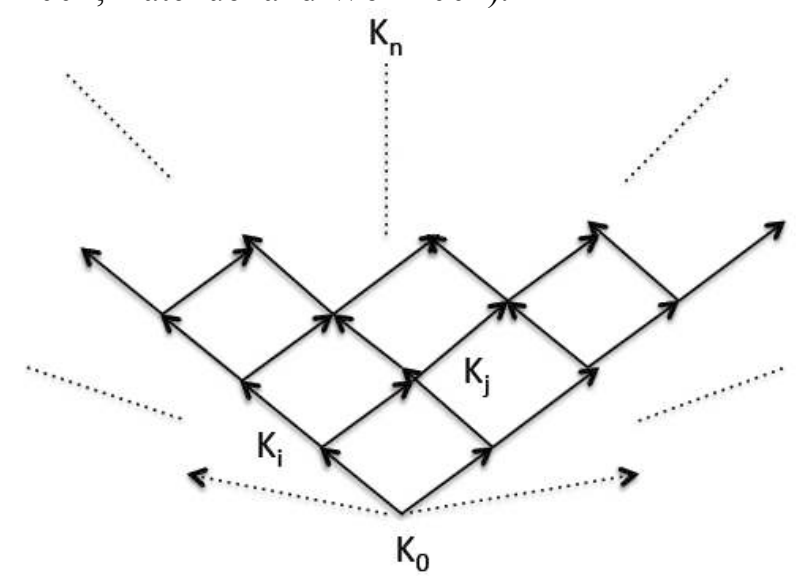

Figure 3. The evolution of knowledge in Intuitionist mathematics.

\subsubsection{Allowing expansion of objects by free choices}

Brouwer introduced incomplete objects (Niekus 2010) in mathematics with his singular approach to continuum. The nature of continuum (real numbers) and infinity has been one of the major challenges of mathematics since Cantor. In order to attain the full richness of continuum while preserving the constructive nature of mathematics, Brouwer proposed the mental operation of 'free choices'. From a design theory standpoint, here lies the most striking feature of Intuitionist mathematics. Allowing an act of free choice at any moment and the possibility to break away from any fully determined (lawlike) object allows the consideration of partially determined objects with novel properties. This offers the possibility to create new mathematical objects at will and it provides the most eminent and original characteristic of Intuitionist Mathematics. It expands the frontier of the Intuitionist continuum from the reduced continuum to full continuum since the totality of mathematical objects that can be defined can no longer be determined in advance. There is always the possibility to continue defining a sequence in a way that distinguishes it from all the others that are known so far, creating thus a novel object (van Dalen 2005). In terms of $\mathrm{C}-\mathrm{K}$ theory, this is the same precise idea of expandable design spaces (Hatchuel 2002; Hatchuel and Weil 2009). With the introduction of free choices and lawless sequences, Brouwer extends an enumerable space, the reduced continuum, to an uncountable and infinitely expandable space, the full continuum. Hatchuel (2002) claims that uncountable sets form the basis of design expansions and the apparition of new objects and definitions. The operation of free choices can thus be seen as the basic mechanism that allows expanding the mathematical design space and that enables the expandable rationality that is inherent to design (Hatchuel 2002; Hatchuel and Weil 2009) within mathematics.

\subsubsection{Interplay of undecided propositions and constructions}

Although Brouwer does not explicitly suggest a particular notion that corresponds to concepts in $\mathrm{C}-\mathrm{K}$ theory, undecided propositions are indeed very much present in Intuitionist Mathematics. It should be noted that undecided propositions in Intuitionist mathematics are not just about propositions whose truths values may be discovered later on. Brouwer makes active use of them, most notably in his counter-examples, in order to construct strange objects whose definitions depend on some undecided properties. The 
method he uses, called "creative subject", consists in the construction of an infinitely proceeding sequence $A(n)$ whose values are not determined in advance but depends on some property $P$ - which is undecided. The truth-value of this proposition depends on the future constructions of the creating subject. Brouwer used this type of sequences to give some of the most spectacular results of Intuitionism such as the (strong) counterexamples to double negation principle (i.e. $\sim \sim P \rightarrow P$ ). In terms of $\mathrm{C}-\mathrm{K}$, such objects have not been $\mathrm{K}$-validated; they do not have a logical status.

By separating the notion of set to its intensional and extensional components (i.e. species and spreads), Brouwer comes even closer to capturing the impact of undecided propositions in design reasoning. While spreads provide a general means to construct new objects extensionally, species whose existence are not known at the current stage conduct and orient this construction. This interplay of spreads and species is reminiscent of the interplay of concepts and knowledge. A creative subject may very well construct (or at least, attempt to construct) new objects by means of spreads and free choice sequences in order to prove the existence of some species. Reciprocally, she can conceive some undecided species for which to look for a proof (a method to construct an object that fits a species). This possibility, together with the use of free choices and undecided propositions, confer to Brouwer's theory the necessary features to take into account creative acts in the constructive mathematical process.

\subsection{Theory of creative subject: a reductionist interpretation of intuitionist constructivism}

Our analysis reveals that the mathematical activity Brouwer is describing is a kind of design process. It is indeed interesting from a design theory perspective since Intuitionism integrates both creative and constructive acts. However, this element has been missed in the traditional interpretations of Brouwer's work. For instance, arguably one of the most genuine innovations he introduces, the creative subject method, relies on the use of propositions with unknown status in order to allow the possibility of future creations and discoveries. Despite this fact, his process description has been interpreted and modeled as a learning process rather than a creative one.

Let us consider one such interpretation. The method of creative subject has been formalized by (Kreisel 1967) and developed further by (Myhill 1968) and (Troelstra 1969). The formalization is based on the "passing of time" and the "knowledge stages" of the creative subject. The stages are enumerated according to the succession of natural numbers. For every $n$ and every $P$, either the subject $S$ has a proof of $P$, or $S$ does not have a proof of $P$ (for each proposition, we are always certain whether we have a proof of it or not). Having a proof of $P$ at stage $n$ is denoted $S_{n} P$. The following formulae try to capture the reasoning process of a creative subject ${ }^{3}$ :

- $\quad \exists n S_{n} P \rightarrow P$, if we have a proof of $P$ (we are able to construct an object such that $P$ holds for it) at some stage $n$, then $P$ is true

- $\quad\left(S_{m} P\right.$ and $\left.n>m\right) \rightarrow S_{n} P$, if at some stage $m$ we prove (and learn) $P$, then, at later stages $n>m$, we still know $P$

- $\quad P \rightarrow \sim\left(\sim \exists n S_{n} P\right)$, if $P$ is true, it is absurd to say that $S$ will never have a proof of $P$

- $\quad P \rightarrow\left(\exists n S_{n} P\right)$, if $P$ is true, then $S$ will certainly have a proof of it in time

The first formula imposes a principle of non-failure for proofs. The second formula represents a principle of accumulation of knowledge: what is learned is never forgotten. The third formula reflects the idea that if an object with a certain property can be

${ }^{3}$ Let us remark that although some controversies have arisen out of this formalization, this poses no problem for the needs of the current discussion. 
constructed, then, there is no reason to think that it shall never be constructed with time. The last formula, a stronger version of the third, states that if an object with a certain property can be constructed, then, eventually the creative subject will construct it.

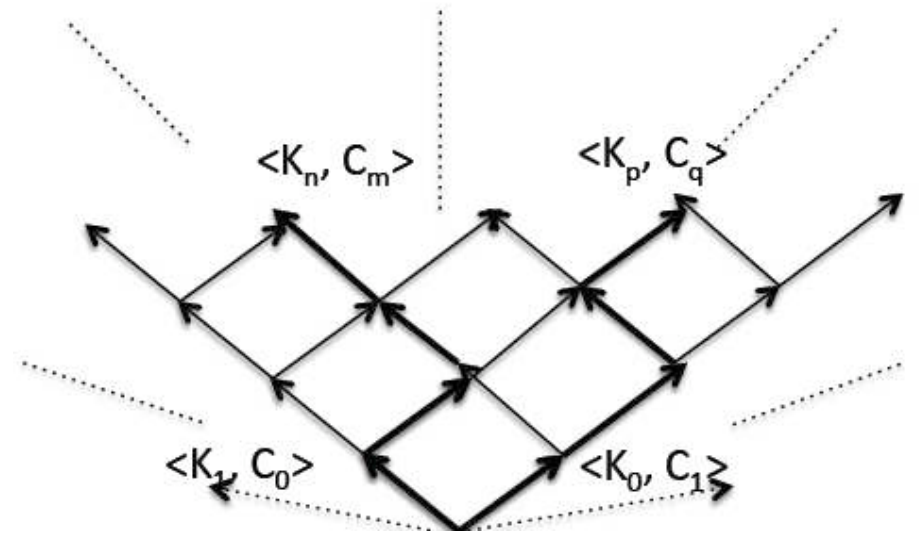

Figure 4. The dual co-evolution of concepts and knowledge and two creative subjects evolving differently through knowledge and concept stages.

Based on our design-theoretic analysis of Intuitionism, it is possible to see that theory of creative subject is restrictive in its interpretation of the reasoning process Brouwer describes. The underlying point of view inherent to these formulas is surprisingly limitative: This seems to be merely a model of learning with some strong assumptions. TCS states that, if $P$ is true (that is, provable), we will certainly have a proof of it at some stage. If every proposition $P$ will certainly be proved at some point, then, where is the creativity of the creative subject? Although the learning over the time aspect is included in TCS model, the creativity of the subject appears nowhere. For instance, the model totally neglects the notion of free choices. It makes no attempt at explaining what guides the progression of proof construction. It makes no assumptions about the impact of what is not known but can be conceived, at a given moment, on how the learning will progress; Figure 4.

For a conception of mathematics where mathematics is the study of mental mathematical constructions resulting from the reasoning process of a subject, it becomes legitimate to consider "directions of learning" and their impact on reasoning. As we can see from the correspondences with $\mathrm{C}-\mathrm{K}$ theory, in the Intuitionist reasoning process, the questions "which propositions should be rather proven?" and "what has been learned so far?" mutually influence each other. For any given stage of knowledge of the subject, the choice of $P$ to be proven next would depend on that stage. Some truths may be more easily accessible or valuable than others, given a stage. On the other hand, the choice of the undecided proposition to be proven may enable or constrain what truths would be more or less easily accessible in the next stages. Consequently, two creative subjects "choosing" to learn about different undecided propositions may evolve significantly different; Figure 4. As this interplay of undecided propositions with proof constructions is not taken into account by TCS, this model does not apprehend the totality of the constructivism Brouwer describes.

\subsection{Intuitionist reasoning as a form of imaginative constructivism}

The mathematical philosophy Brouwer introduced is an early approach to constructivism from which other constructivist approaches have benefited (Bishop 1967; Martin-Löf 1984). As we have seen with the analysis on TCS, it has often been interpreted as a form we shall call pure constructivism where new objects are simply a bottom-up combination of previously constructed objects. In this interpretation, a monotonic learning process accumulates knowledge. Intuitionism provides a richer picture of the creative constructivist process. By allowing conceivable but undecided propositions, it offers a basic form of an imaginative constructivism where bottom-up constructions are not 
necessarily lawlike and they can be combined with top-down processes (i.e. the generation and use of undecided propositions). A creative subject may alter the bottom-up construction process by unexpected elements in order to construct objects with surprising properties. This gives the theory the possibility to expand the repertory of known objects in new ways. With these features, it provides a powerful alternative to the classical mathematics by allowing partially defined objects and considering the continuum in its richest form without putting in jeopardy its constructivist nature.

It should be noted that Intuitionism does not distinguish between the construction of definitions and the construction of the actual objects. Although Brouwer defines mechanisms (such as the free choices) for constructing objects, he does not explain how the idea of such objects appears, nor does he describe how these ideas develop over time. Although he considers the possibility of free choice in constructing new objects, he does not explain that such free choices go hand in hand with the choice of new concept of objects. It is not considered explicitly in Intuitionist Mathematics how the choice of the properties to be proven (or how these properties are chosen) may affect the next stages of the subject's activity. From the view point of C-K theory, this is a lacking feature for explaining creative reasoning processes (mathematical or not; (Kazakci and Hatchuel 2009)). However, it should be recognized that this is to be expected: Brouwer's intention was to develop and expose an alternative way of practicing mathematics; it was not to describe the creative process itself. Nevertheless, the principles he established authorize the use of undecided propositions and Brouwer himself uses them in various ways, for example, by constructing propositions whose truth depends on undecided propositions. It is this possibility to juggle with the top-down generation of new species and the bottomup construction of objects that give the mathematician, as shown by Brouwer's own demonstrations, the possibility to conduct an imaginative constructivist reasoning process.

Such dynamics are reminiscent of the distinction between the formulation of a theorem and its demonstration by a proof. It is known in mathematics that, in some cases such as Fermat's last theorem, there have been several centuries between the two processes. In design literature, it is possible to find cases that highlight similar dynamics. For instance, Eris (2006) describes an example of the human flying machine of Leonardo da Vinci that inspired centuries later Daedalus built by NASA engineers. Examples such as this one are indicative that there may be various processes of construction in design processes (e.g., the construction of a definition vs. construction of an actual object). Recent experimental data (Eris 2004 ; Edelman 2012) also supports the idea that designers think and act differently when thinking about what the object should be or how the object can be built (Kazakci 2010). The imaginative constructivist dynamics we have described allow thus to reveal a dual constructivism in design processes. This issue has been under-investigated in design literature, often collapsing both notions into a single one. Although theories of co-evolution (e.g. problems-solutions, concepts-knowledge, functions-structures) exist in design literature (Maimon and Braha 1996; Braha and Reich 2003; Hatchuel and Weil 2009), either they do not explicit the constructive aspects or they do not take into account the free-choices of the designer.

\section{Design as imaginative constructivism}

Based on the previous discussions, we have now some formal grounds based on which we can discuss the 'constructivist' nature of design and its different manifestations. The analysis of the previous section accounted for a strong connection between creative acts and the construction of objects in intuitionist mathematics. The notion of imaginative constructivism we have identified involves projecting a yet-to-exist future state and progressing towards it with construction attempts. When apprehended from a design reasoning perspective, the process that is described in intuitionism offers indeed a set of interesting notions that may be useful for analyzing both formal theories about design and 
actual design situations with strong innovative components. We shall now discuss one such design project, namely, the Manhattan Project and the making of an atomic bomb (Lenfle 2008, 2011). Although the consequences of Manhattan Project were tragic and burns like a scar in the collective consciousness of mankind, the making of an atomic bomb remains nevertheless a colossal scientific and engineering feat. During the project a huge number of new objects and processes were designed for the first time in the human history. Many of these objects, such as the barriers for uranium separation or implosive bombs, were breakthrough innovations by themselves. Such big-science projects (Weinberg 1961, 1963) have been used in recent management literature to demonstrate that traditional approaches to project management are unable to cope with design processes that requires fundamental breakthroughs (Lenfle 2008, 2011). The extremely innovative nature of this project makes it suitable for discussion in relation to the concept of imaginative constructivism and contrasting it with other notions of design constructivism we have identified.

\subsection{A 'theory' called fission: a seed for an imaginative project}

From 1932 to 1939, several prominent researchers such as Chadwick and Fermi laid down the theoretical foundations for nuclear reaction. In particular, (Meitner and Frisch 1938) proposed a process that can start a chain reaction starts when released neutrons hits further atoms, splitting them again, which release further neutrons and energy and so on. Meitner and Frisch called the principle 'fission' in analogy with the splitting of the cells in biology. Their work provided a major impetus for the undertaking of an atomic bomb project, since, if the tremendous potential energy predicted by the theory could be used as a weapon, the war could be ended. Although, it is not certain that fission can be obtained successfully, within the context of the world war, a novel definition - 'a bomb that would achieve previously unseen power using fission based chain reaction' - was formulated

(Lenfle 2008, 2011).

It should be noted that the fission theory formed a seed for this imaginative proposition. As Groves (Groves 1962) noted "the whole endeavor was founded on possibilities rather than probabilities. Of theory there was a great deal, of proven knowledge, not much". Scientists and engineers had to admit in some cases that their estimates and predictions would be accurate within a factor of ten. From a scientific point of view, issues that need to be addressed were not a specific research problems but rather entire fields of exploration that would need to be studied for years to come. Also, there were significant engineering problems that this theoretical model induced, for example, about how to attain a critical mass of fissionable material and how to control the number of neutrons released each step (Lenfle, 2008, 2011).

In that moment, the proposition $P$ about the possibility of an atomic bomb was yet an undecided proposition. On the one hand, it was not possible to rule out the possibility of building such a device, since the theories, although yet to be verified, were predicting such a possibility. On the other hand, it was not known how to 'construct' such an object. Recalling that, in intuitionist terms, a proof is a method of construction, the proposition opened a path to an imaginative constructivist process. Considering the internally consistent theories, a proposition that holds great value has been formulated, even though within the known set of 'methods' (or any combination thereof) there was not any immediate possibility of construction for such an object. We can also recognize here that this is a situation where failure to prove some propositions cannot lead to the conclusion it can never be proven. As later examples will illustrate, within this intensive innovation context where knowledge is extremely scarce about the objects of innovation, the law of the excluded middle cannot be held to be a valid principle. 


\subsection{A massively generative exploration process: enabling and driving power of imaginative propositions}

Despite this lack of knowledge, two main propositions have been formulated as the primary branches of the project: there is a process by which fissionable materials can be produced $(Q)$ and there is a process by which a device that would detonate fissionable materials can be produced $(R)$. Note that these processes fit the Intuitionist description of a proposition. What was sought were 'methods' that would transform in a number of steps a certain set of inputs (already constructed objects), such as the Uranium or the bomb shell, to a desired output - a 'constructive proof' is required to verify not only the existence of objects that would make the propositions true but also indicating how to build them. Considering the profound lack of knowledge that has been pointed out, for both processes, a step by step construction that would allow the transformation of the inputs into the desired outputs were not known. However, as Lenfle explains (2008, 2011), several alternative paths to be explored were identified.

For fissionable materials, either U235, a derivation of natural uranium (U238), or Plutonium (Pu239) a by-product of nuclear fission were the two candidates. Separation of U235 from U238 involves extremely complex processes based on the variations in the atomic masses of the two isotopes. Seven different methods were under investigation, only three of which finally worked. Plutonium, discovered only one year before the start of the project, seemed to be more interesting for nuclear fission, but its production required the construction of nuclear reactors and associated chemical separation plants. Once again, this was an unchartered territory. The processes for plutonium did not exist before the process and chemical separation had never been applied to radioactive materials. Twelve different processes were studied. Aside the uncertainties on the possibility of producing these materials, there were also tight requirements for safety and sustainable mass production that increased the level of precision needed even further (Lenfle 2008).

For the bomb design, three different propositions were being investigated (Lenfle 2008, 2011). The 'gun' method was a well-mastered method. The principle is that a piece of fissionable material is thrown to another piece by means of traditional explosives. The colliding fissionable materials become critical and a chain reaction starts. The 'implosion' method was a breakthrough innovation in weapon design. It consists in placing a plutonium core inside traditional explosives which, when detonated, blow inward, thus causing a collapse of the core that attains the critical mass. The 'super' method was another breakthrough design that relies on nuclear fusion rather than fission. Its design, inspired from the functioning of the stars, required a fission bomb to start a nuclear fusion reaction based on Deuterium or Tritium.

Note that in the beginning of the project, the mentioned possibility of separation and enrichment methods, as well as the mechanism of the bomb are again undecided propositions. Moreover, it can be noted that the existence of the primary imaginative proposition $P$ is made conditional of their existence. This is similar to Brouwer's famous counter-examples where some undecided property (such as the convergence of a real number) depends on some other undecided propositions (such as the existence of a particular sequence in the decimal expansion of $\pi$ whose existence is unknown at that step of the reasoning). Depending on the provability of the later, the original proof will be decided. Thus, the choice of these dependences reflects an important aspect of the design strategy. Remark that this is not a decomposition strategy, quite the contrary: the path to the proof for the imaginative proposition is being composed by means of other yet-to-beproven imaginative propositions.

From this summary of main issues considered within the project, it can be concluded that a wealth of new scientific and engineering concepts were being considered 
simultaneously (Lenfle 2008, 2011). An important number of solution principles to be investigated had been identified for each proposition. In each case, even though the proof could not be immediately made, the propositions helped to generate issues to be explored. The project progressed with an abundance of knowledge produced, some of which were not useful for the project at hand. Nevertheless, the imagined propositions were guiding the learning process and the progression through stages of knowledge. Said in other terms, the imaginative propositions drove the construction attempts.

\subsection{Failed proof attempts and generation of alternative proofs}

In the spring of 1944, several big crises led the project to a deadlock. Several problems were discovered about uranium enrichment methods. The 'barrier problem' was about the separation process of uranium 235 from uranium 239. The major concept behind the efforts was pumping the uranium against a porous barrier that would retain slightly bigger U239 elements while U235 passes through. This proved to be a much more challenging project than expected. Smyth (Smyth 1945) writes in his report that the barrier in the gaseous diffusion processes "must have almost no holes which are significantly larger than 0,001 micron, but must have billions of holes of this size or smaller. These holes must not enlarge or plug up as the result of direct corrosions or dust coming from elsewhere in the system. The barrier must be able to withstand pressure of a head of one atmosphere. It must be amenable to manufacture in large quantities and with uniform quality." This proposition that looks more like a traditional design specification is still an undecided proposition by then. Despite all efforts, alternatives envisaged for the barrier, the Norris-Adler barrier made from electroplated nickel and the Kellex barrier made with compressed nickel powder would not meet these requirements.

A second problem concerning the production of fissionable materials was the 'Xenon poisoning' problem. In September 1944, right after the start of Plutonium production reactor, the reactivity of the pile declined then died for a few hours. Then, came back to life, started to decline again and so on. This was completely unanticipated. The team soon suspected a poisoning problem that led them to discover that, Xenon, a by-product of chain reaction, was being produced during the process, absorbing the neutrons, stopping the pile and disappearing in the process... until the pile becomes reactive again.

Yet another major obstacle became apparent about the bomb's working principle. It was believed that the gun method could be used both with uranium and plutonium. Since plutonium was less well known, most of the efforts concentrated on plutonium assuming that if it worked with plutonium, it would directly work with uranium with minor modifications. It was soon discovered that the plutonium has a much higher spontaneous fission rate than uranium. This means that, unless the two parts of the gun collided extremely quickly, the chain reaction might start early and the bomb fizzles (i.e. predetonate and does not explode). While this possibility was anticipated even at the beginning, precise knowledge about the phenomena was absent and most of the efforts during the project needed to focus on this issue. The entire plutonium path was blocked (with the gun design), at a time when the separation of U235 encountered major problems (Lenfle, 2008, 2011).

\subsection{Decisive impact of free choices in the Manhattan project}

Eventually, the problems have been circumvented. But the ways alternative proof paths have been obtained were quite different in each case. None of the paths explored for the uranium enrichment process had been satisfactory enough. But, in 1944, following important advances on thermal diffusion process - an alternative method for enrichment not considered in the project until then, Oppenheimer suggested that different processes could be combined. After considering several different ways to combine different types of processes, finally, a satisfactory process was found. Note that this step of the proof would have been an ordinary planning problem (i.e. finding the optimum sequence of methods), 
had it been the combination of already known methods. Even when the sequences of these processes were being configured there were many unknowns on each of those methods. As Thayer puts it they "could never afford the luxury of awaiting the proof of one step before proceeding with the next". All the methods were still being invented while they were being combined, which is a distinct characteristic of innovative design (Kazakci et al. 2010)

For the barrier problem, competing processes that were being investigated could not be validated despite huge efforts. A combination of them was not possible, contrary to the enrichment process, since there was little sense in feeding the output of one process to the other. Eventually, a third kind of barrier combining best features of the two proposals has been used (Qiang 1996). This is yet another way the proof has been accomplished, since the process used was not a resequencing of steps, but a new kind of method - a new species. This is reminiscent of conceptual blending (Fauconnier and Turner 2002) where features from conceptually distant solutions can be combined to form new and original concepts.

One of the most striking constructions of the entire project was yet the implosion based bomb design that solved the spontaneous fission crisis. The implosion method is conceptually so different from the originally attempted proofs (i.e. variations of the traditional gun method) that it cannot be qualified as a combination of known or candidate methods, nor a blending of suitable features. Its working principle is conceptually independent from that of the gun method. In fact, it can be seen as a new type of object, a 'species', that is even independent of the Manhattan project itself. This can be understood from the fact that, while all the other issues related to the bomb design with fissionable materials were issues related to nuclear physics, the implosion method was first and foremost a hydrodynamic problem. The possibility to construct an example of this species was mentioned right from the beginning of the Manhattan project, when scientists held a workshop on bomb design at Berkeley in July 1942. Nevertheless, efforts were concentrated elsewhere and although the implosion method was an imaginative proposition promising great efficiency at that moment, it was far from being a proven concept. When the spontaneous fission crisis appeared, Groves takes the decision to integrate the 'implosion method' proposition with that of the 'atomic bomb' proposition, making thus the latter species dependent on the former. Once again, the proof followed the proposition later on: In July 1944, Oppenheimer, in charge of critical mass calculations and weapon detonation, reorganized completely his laboratory according to the structure of this proposition, instead of the traditional research based structure. The implosion method proposition evolved quite significantly and in various directions during this two years period. Eventually a version proposed by Von Neumann in fall 1943 helped to unlock the path to the proof, based on the idea of using explosive lenses to focus the explosion onto a spherical shape using a rapid succession of slow and fast explosions. The free choice by Groves on connecting the two species had to be proven with the free choices of Von Neumann and colleagues.

\subsection{Discussion: imaginative constructivism vs. other forms of constructivism in design}

The case study illustrates how notions from intuitionist constructivism allow capturing and emphasizing some of the fundamental properties of a strongly innovative design process. We believe that these properties are generic properties of any design process that combines creative and constructive acts. As can be observed from the description of the case, one of the properties of such a process, that we have labeled as imaginative constructivist, is the separation between the construction of the definition of an object from the construction of a method to build an object verifying that definition.

As concluded from our analysis of Brouwerian mathematics, the notion of imaginative constructivism also posits that in both types of reasoning activities the designer can inject 
unanticipated and surprising elements into the on-going construction in order to either change the definition of the object in a significant way or the method of construction to warrant (or, at least to progress towards) feasibility.

We have seen an example of those contrasting processes in the differences between the barrier problem and the explosion principle. The barrier problem was circumvented with a novelty that changed the 'method' of production. In the end, the solution obtained, even though a genuine scientific and engineering feat, was easily recognizable as a 'filter' which was the type of object targeted right from the beginning. Yet, concerning the bomb's working principle, the solution came both from a significant change in the definition - creating definitely a new type of bomb - and an ingenious method allowing to obtain the targeted effect, after several alternatives that have been explored.

A major conclusion that can be drawn from the analysis is that other forms of constructivism we have identified cannot fully account for these process properties. Naturally, designers of Manhattan project have interacted with various types of representations (ranging from sketches and schemas to full scaled prototypes) during the project. But we do not believe that the variety of thinking processes that took place in Manhattan project can be captured by this notion alone. These imaginative propositions were not inferred, nor discovered by a perceptual rearrangement of some cues in the immediate surroundings of the designers. An example like the implosion method is not just an inflexion point changing the trajectory of reasoning. It is a rupture in the reasoning process that can rather be taken into account by a notion of free choice from a creative subject. This rupture is beyond a notion of design move as it is defined by (Schön, 1983) in that it emphasizes both the unpredicted and the unpredictable nature of a sequence of moves that significantly transforms the process. Although intuitionism does not explain how free choices are possible, it does in the very least recognize that they are possible and they are the mark of genuine creative acts that break away from any current laws and preestablished algorithms.

Nor does the notion of negotiation of different object-world views make full justice to what has happened. In a social constructivist view of design there is an extensive emphasis on the communicative aspects of design. Surely, as in many other human enterprises, communication had a crucial role in the advancement of the project. However, this idea does not allow capturing that the experts involved with the project not only shared their knowledge to reach a shared understanding or to negotiate tradeoffs, but also their imaginative propositions. In a design process where the aim is a breakthrough innovation, necessarily design cannot be reduced to the application of technical knowledge, but, nor can it be reduced to communication and interfaces. It becomes indispensable to be able to formulate imaginative propositions and to reach a collective commitment to elaborate them, fueled by the expertise and imagination of each individual. A distinct example of the effect of such commitment can again be found in the Manhattan project case. Of the two greatly imaginative propositions regarding the detonation methods, implosive and super, only the former has been a proposition which generated sufficient commitment during the project, even though the latter seemed to be much more promising in theory. Considering the fact that at the beginning of the project many people did not think that the implosive design was a viable alternative, we cannot say that it was the feasibility concerns that blocked the way to the 'super'. In fact, as (Bethe 1982) explains, Teller who proposed the 'super' concept was obsessed with this concept but he was seen as a person who would waste important resources and time on a problem because of personal and theoretical interest. Considering the fact that the concept of super has been realized later and it is known today as the hydrogen bomb, we can see that it was more of an issue of sharing the imaginative proposition and building a commitment towards it - a dimension that is lost when only expertise and knowledge are considered as in social constructivism. 
We should note, however, that, none of the above arguments is meant to imply that imaginative constructivism is more general or important than interactive and social constructivism in design. Rather, we believe it transcends and complements those forms in any occurrences of design, be it individual or in groups, within situated or social efforts - by bringing in additional nuances that captures significant aspects of design.

Finally, we should note some limitations of our comparison and our use of Brouwer's work as a metaphor to understand design. In fact, the forms of constructivism that we have identified have been traditionally studied at very different levels of observation. The interactive constructivism has usually been treated at an individual level whereas the social constructivism considers mainly small teams of designers. In the Manhattan project, thousands of people were involved. We believe however that this is only an apparent limitation since all the forms of constructivism that we mentioned can appear in all different scales of design activity. Our aim in using an extreme case both in size and results was to emphasize that the imaginative aspects are ubiquitous regardless.

Another limitation comes from the absence of some notions in Brouwer's constructivism. For instance, the distributed nature of reasoning and acting do not appear in his constructivism, since he focuses on an individual mathematician. Similarly, the notion of resources used in the process is lacking. It should be noted that massive resources have been allocated to the Manhattan project. Groves' main strategic approach to the project was to explore several and costly candidate proof paths in parallel. If the project had been undertaken with more limitations the history might have taken another turn. However, we do not believe these issues reduces the utility of the metaphors intuitionism provides, since, as we have demonstrated through the case, we can use them naturally to describe the main points of the design reasoning nevertheless.

\section{Summary}

The present contribution can be seen as a contribution to the program announced by (Reich et al. 2008). They claim the necessity and potential benefits in investigating the relationship between mathematics and design. In design literature, many such efforts exist, e.g. general design theory of (Yoshikawa 1981) or topological spaces (Braha and Reich 2003). Our approach is different from those works: while they borrow ideas and methods from mathematics for modeling and explaining design, we utilize notions and ideas from design theory for interpreting and discussing mathematics to gain insight into a notion that we deem important for design research - constructivism.

Our theoretical analysis of the roots of intuitionism has revealed a dual constructivism on the definition of objects and the methods by which they are constructed. This type of process we labeled imaginative constructivism involves the articulation of top-down (the generation of undecided and new propositions) and bottom-up (combination of existing objects) processes. Both the construction of definitions and the construction of methods may be changed significantly during the activity by the free choices of the designer.

Based on the discussion of an historical and innovative design case, the making of the first atomic bomb, we have discussed the relevance of these notions for capturing and describing design reasoning. We also compared the creative constructivist approach derived from the intuitionism with two other forms of constructivism we have identified in the literature. We have concluded that imaginative constructivism transcends and complements social and interactive constructivism found in the literature, by capturing explicitly the breakthrough creativity in the design process.

\section{Acknowledgements}

The author would like to thank to Joop Niekus, Mark van Atten, Anne-Françoise Schmid, Thomas Gillier, Armand Hatchuel and the anonymous referees for helpful comments on earlier versions. 


\section{References}

Anderson, M. L. (2003). "Embodied cognition: A field guide." Artificial Intelligence 149(1): 91130.

Benacerraf, P. (1965). "What Numbers Could Not Be." The Philosophical Review aul (1965) What Numbers Could Not Be, The Philosophical Review, 74:47-73.(74): 47-73.

Benacerraf, P. and H. Putnam, Eds. (1983). Philosophy of mathematics: selected readings. Cambridge, Cambridge University Press.

Bethe, H. A. (1982). "Comments on The History of the H-Bomb." Los Alamos Science 3(3): 47.

Bishop, E. (1967). Foundations of Constructive Analysis. New York, Academic Press.

Braha, D. and Y. Reich (2003). "Topological structures for modelling engineering design processes." Research in Engineering Design 14: 185-199.

Brouwer, L. E. J. (1907). Over de Grondslagen der Wiskunde [On the foundations of Mathematics], 183p.

Brouwer, L. E. J. (1908). "De Onbetrouwbaarheid der logische principes." Tijdschrift voor Wijsbegeerte 2: 152-158.

Brouwer, L. E. J. (1948). Consciousness, Philosophy and Mathematics. Proceedings of the 10th International Congress of Philosophy, Amsterdam.

Brouwer, L. E. J. (1952). "Historical Background, Principles and Methods of Intuitionism." South African Journal of Science 49: 139-146.

Bucciarelli, L. (1988). "An ethnographic perspective on engineering design." Design Studies 9(3): 159-168.

Bucciarelli, L. (1994). Designing the engineers. Cambridge, MA, MIT Press.

Bucciarelli, L. (2002). "Between thought and object in engineering design." Design Studies 23(3): 219-231.

Burgess, J. P. and G. Rosen (1997). A Subject with No Object: Strategies for Nominalistic Interpretation of Mathematics, . Oxford, Clarendon Press, .

Chihara, C. (1990). Constructibility and Mathematical Existence. Oxford, Oxford University Press.

Clancey, W. J. (1997). Situated cognition : On human knowledge and computer representations. New York, NY, USA, Cambridge University Press.

Davis, J. G., E. Subrahmanian, S. L. Konda, H. Granger, A. Dutoit, C. M and A. W. Westerberg (2001). "Creating shared information spaces to support collaborative design work." Information Systems Frontiers 3(3): 377-392.

Dougherty, D. (1992). "Interpretative barriers to successful product innovation in large firms." Organization Science 3(2): 179-202.

Dummett, M. (1977). Elements of Intuitionism. Oxford, Clarendon Press.

Edelman, J. A. (2012). Understanding radikal breaks through media. Phd Thesis Stanford University.

Edmonds, E. A. and L. Candy (1999). Computation, Interaction and Imagination: Into Virtual Space and Back to Reality. Proceedings 4th International Roundtable Conference on Computational Models of Creative Design.

Eris, O. (2004 ). Effective Inquiry for Innovative Engineering Design. Boston, Kluwer.

Eris, O. (2006). "Insisting on Truth at the Expense of Conceptualization: Can Engineering Portfolios Help?" International Journal of Engineering Education 22(3): 551-559.

Evbuomwan, N. F., S. Sivaloganathan and A. Jebb (1996). "A survey of design philosophies, models, methods and systems." Journal of Engineering Manufacture 210: 301-320.

Fauconnier, G. and M. Turner (2002). The Way We Think: Conceptual Blending and the Mind's Hidden Complexities. New York, Basic Books.

Field, H. (1980). Science Without Numbers: A Defence of Nominalism. Princeton, N.J., Princeton University Press.

Fraser, Z. (2006). "The Law of the Subject: Alain Badiou, Luitzen Brouwer and the Kripkean Analyses of Forcing and the Heyting Calculus." Cosmos and History: The Journal of Natural and Social Philosophy 2(1-2): 94-133.

Frege, G. (1983). The concept of number. Philosophy of mathematics: Selected readings. P. Benacerraf and H. Putnam. Cambridge, Cambridge University Press.

Freudenthal, H., Ed. (1976). Collected Works 2. Geometry, Analysis, Topology and Mechanics. Amsterdam, North Holland Publishing.

Gero, J. and J. Kulinski (2000). A situated approach to analogy in designing. CAADRIA2000. B.K. a. T. Tang, M. and Wong, Y-C. CASA, Singapore: 225-234. 
Gero, J. S. (1998). Conceptual designing as a sequence of situated acts. Artificial Intelligence in Structural Engineering, Information Technology for Design, Collaboration, Maintenance, and Monitoring. I. Smith, Springer: 165-177.

Groves, L. (1962). Now It Can Be Told: The Story of the Manhattan Project. New York, Harper. Hatchuel, A. (2002). "Towards Design Theory and Expandable Rationality: The unfinished program of Herbert Simon." Journal of management and gouvernance 5(3): 260-273.

Hatchuel, A. (2008). Mathématiques et conception, par Armand HATCHUEL. Les nouveaux régimes de la conception: Langages, théories, métiers. A. Hatchuel and B. Weil. Paris, Edition Vuibert.

Hatchuel, A. and B. Weil (1999). Pour une théorie unifiée de la conception, Axiomatiques et processus collectifs. CGS Ecole des Mines, GIS cognition-CNRS.

Hatchuel, A. and B. Weil (2002). La théorie C-K: Fondaments et usages d'une théorie unifiée de la conception. Colloque Sciences de la Conception, Lyon.

Hatchuel, A. and B. Weil (2003). A new approach of innovative design : an introduction to C-K design theory. ICED'03, Stockholm, Sweden.

Hatchuel, A. and B. Weil (2007). Design as Forcing:Deepening the foundations of Ck theory. 16th International Conference on Engineering Design - ICED 2007, Knowledge, Innovation and Sustainability, Paris, France.

Hatchuel, A. and B. Weil (2009). "C-K design theory: an advanced formulation." Research in Engineering Design 19(4): 181-192.

Hendriks, L. (2010) "Imagining Future Knowledge, Logic and Interactive Rationality Seminar, The Institute for Logic, Language and Computation, University of Amsterdam ."

Hendriks, L. and A. Kazakci (2010). A formal account of the dual expansion of concepts and knowledge in C-K theory. International Deisgn Conference - Design 2010, Dubrovnik - Croatia

Hendriks, L. and A. Kazakci (2011). Design as Imagining Future Knowledge, a Formal Account. LIRA seminar.

Heyting, A., Ed. (1975). L.E.J. Brouwer. Collected Works 1. Philosophy and Foundations of Mathematics. Amsterdam, Heyting, A. (Ed). North Holland

Heyting, A. (1983a). Disputation. Philosophy of mathematics: selected readings. P. Benacerraf and H. Putnam. Cambridge, Cambridge University Press: 66-76.

Heyting, A. (1983b). The intuitonist foundations of mathematics. Philosophy of mathematics: selected readings. P. Benacerraf and H. Putnam. Cambridge, Cambridge University Press: 52-61.

Hilbert, D. ( 1927). The foundations of mathematics. Ewald, William B., ed., 1996. From Kant to Hilbert: A Source Book in the Foundations of Mathematics, 2 vols. Oxford Uni. Press.

Kazakci, A. (2009). A formalisation of CK design theory based on Intuitionist Logic. International Conference on Research into Design. ICORD09. A. Chakrabarti. Banglore, India, Research Publising Services: 499-507.

Kazakci, A. (2010). Imaginative constructivism in design. Mission report on visit to CDR at Stanford University. . TMCI, CGS, Mines ParisTech, Paris.

Kazakci, A. and A. Hatchuel (2009). Is "creative subject" of Brouwer a designer? - an Analysis of Intuitionistic Mathematics from the Viewpoint of C-K Design Theory., International Conference on Engineering Design, ICED'09, , Stanford CA.

Kazakci, A., A. Hatchuel, P. Le Masson and B. Weil (2010). Simulation of Design reasoning based on $\mathrm{C}-\mathrm{K}$ theory: a model and an example application. International Design Conference Design 2010. Dubrovnik - Croatia.

Kreisel, G. (1967). Informal rigour and completeness proofs. Problems in the Philosophy of Mathematics. Lakatos. Amsterdam, North Holland Publishing Company: 138-186.

Kripke, S. (1965). Semantical Analysis of Intuitionistic Logic I. Formal Systems and Recursive Functions. M. Dummett and J. N. Crossley. Amsterdam, North-Holland Publishing. : 92-130.

Lakoff, G. and R. E. Nunez (2000). Where mathematics comes from: How the embodied mind brings mathematics into being. New York, Basic Books.

Largeault, J. (1993). Intuition et Intuitionisme. Paris, Vrin.

Le Masson, P., B. Weil and A. Hatchuel (2010). Strategic Management of Design and Innovation. Cambridge, Cambridge University Press.

Lenfle, S. (2008). Proceeding in the dark. Innovation, project management and the making of the atomic bomb. Paris, Centre de Recherche en Gestion.

Lenfle, S. (2011). "The strategy of parallel approaches in projects with unforeseeable uncertainty: the Manhattan case in retrospect." International journal of Project Management 24(9): 359-373.

Maimon, O. and D. Braha (1996). "A Mathematical Theory of Design." International Journal of General Systems 27(4-5): 275-318.

Martin-Löf, P. (1984). "Intuitionistic Type Theory." Notes by Giovanni Sambin of a series of lectures given in Padua, June 1980, Bibliopolis, Napoli. 
Meitner, F. and O. R. Frisch (1938). "Lise Meitner and Disintegration of Uranium by Neutrons: a New Type of Nuclear Reaction." Nature 143(3615): 239-240.

Myhill, J. (1968). Formal systems of intuitionistic analysis I. Logic, methodology and philosophy of science III. B. v. Rootselaer and J. Staal. Amsterdam, North Holland Publishing Company. III. Niekus, J. (2010). "Brouwer's Incomplete Objects." History and Philosophy of Logic 31: 31-46.

Qiang, J. (1996). The scientists making the atomic bomb. Pathological States, The Origins, Detection, and Treatment of Dysfunctional Societies: Collected papers of the Ford Foundation Interdisciplinary Research Seminar on Pathological States. S. P. Cohen and K. Cloud. ACDIS//ACDIS FFIRS:3.

Reich, Y., O. Shai, E. Subrahmanian, A. Hatchuel and P. LeMasson (2008). The interplay between design and mathematics: Introduction to bootstrapping effects. 9th Biennial ASME Conference on Engineering Systems Design and Analysis ESDA2008. Haifa, Israel, 2008.

Roozenburg, N. F. M. and C. H. Dorst (1998). Describing Design as a Reflective Practice: Observations on Schön's Theory of Practice. Designers: The Key to Successful Product Development. E. Frankenberger, P. Badke-Schaub and H. Birkhofer. London, Springer: 29-41.

Russell, B. (1903). The Principles of Mathematics. Cambridge, Cambridge University Press.

Russell, B. and A. N. Whitehead (1910). Principia Mathematica. Cambridge, Cambridge University Press. Second edition, 1925

Schön, D. A. (1983). The Reflective Practitioner. New York, Basic Books.

Schön, D. A. and G. Wiggins (1992). "Kind of seeing and their functions in designing." Design Studies 13(2): 135-156.

Smyth, H. D. (1945). Atomic Energy for Military Purposes; the Official Report on the Development of the Atomic Bomb under the Auspices of the United States Government, 19401945 Princeton University Press, Princeton.

Subrahmanian, E., S. L. Konda, S. N. Levy, Y. Reich, A. W. Westerberg and I. A. Monarch (1993). "Equations aren't Enough: Informal Modeling in Design." AI in Engineering Design and Manufacturing 7(4): 257-274.

Suchman, L. A. (1987). Plans and situated actions : the problem of human-machine communication. Cambridge, New York, Cambridge University Press.

Suwa, M., J. S. Gero and T. Purcell (1999). Unexpected discoveries and s-inventions of design requirements: A key to creative designs. Computational Models of Creative Design IV: 297-320.

Suwa, M. and B. Tversky (2003). Constructive Perception: A metacognitive skill for coordinating perception and conception. . Cognitive Science Society Proceedings: 1140-1144.

Troelstra, A. S. (1969). Principles of intuitionism. Berlin, Springer Verlag.

van Dalen, D., Ed. (1981). Brouwer's Cambridge Lectures on Intuitionism. Cambridge, Cambridge University Press.

van Dalen, D. (1999). The role of language and logic in Brouwer's work. Logic in Action. E. Orlovska. Vienna, Springer: 3-14.

van Dalen, D. (2005). "How the Mathematical Objects Determine the

Mathematical Principles1." Journal of Universal Computer Science 11(12): 2132-2141.

Weinberg, A. M. (1961). "Impact of Large-Scale Science on the United States." Science 134 (3473): 161-164.

Weinberg, A. M. (1963). Science, Government, and Information: The Responsibilities of the Technical Community and the Government in the Transfer of Information. Washington, D.C., The president's scientific advisory commitee, White House.

Yoshikawa, H., Ed. (1981). General design theory and a CAD system. Man-Machine Communication in CAD/CAM, North Holland Publishing. 